\title{
Hearing impairment and mental state in the elderly living at home
}

\author{
KATIA GILHOME HERBST, CHARLOTTE HUMPHREY
}

\section{Summary and conclusions}

Altogether $153(60 \%)$ out of a sample of 253 people aged 70 years and over living in their own homes were found to have impaired hearing when tested by pure-tone audiometry. This is almost twice the prevalence found in all other studies, in which deafness was assessed clinically or by self-reporting. The prevalence of deafness increased with age. Evidence of organic brain syndrome (dementia), as determined by questionnaire, was present in $39(16 \%)$ out of 245 respondents, and of depression in $82(35 \%)$. Dementia and depression were both age related. An apparent association between deafness and dementia was shown to be due to age alone. A significant relation between deafness and depression was independent of age and socioeconomic state.

The use of audiometric techniques of assessment established that an association exists between deafness and depression that is not simply a function of differential reporting reflecting the emotional state of the respondent.

\section{Introduction}

No community studies have been conducted in Britain to assess the prevalence of hearing loss in the elderly by audiometric techniques. Instead various studies have relied on the selfassessment of respondents, ${ }^{12}$ or the judgment of the interviewer or clinician. ${ }^{3}{ }^{4}$ Both these methods produce results consistently suggesting that between $30 \%$ and $40 \%$ of the population aged 70 years and over suffer from appreciable bilateral hearing loss. Estimates of this order appear to be used by the Department of Health and Social Security when considering the provision of social services for the elderly with impaired hearing. ${ }^{5} \mathrm{~A}$ relation between hearing loss and mental state in the elderly has been suggested since the seminal study of Kay et al on the possible social and medical causes of mental disorders in old age. ${ }^{6}$ Workers have suggested, firstly, that long-term sensory deficit may play some part in producing symptoms of dementia ${ }^{6}$ ? and, secondly, that deafness may contribute to the precipitation of depression in old age. ${ }^{89}$

We report a study in which a sample of elderly people were examined audiometrically in their own homes and assessed for mental function.

\section{Methods}

The sample consisted of all 365 persons aged 70 years and over registered with a group practice in an inner London borough. Fortyeight refused to take part and 46 were in hospital, on holiday, or untraceable. Eighteen were subsequently excluded from analysis because of inadequate audiometry, poor English, or inebriation. Thus 253 subjects, representing $69^{\circ} \%$ of the sample, were studied.

Department of Applied Social Studies, Polytechnic of North London, London N5

KATIA GILHOME HERBST, MA, research fellow

CHARLOTTE HUMPHREY, BA, MSC, research assistant
Table I shows the age and sex distributions. There were no significant differences between respondents and non-respondents in these distributions.

TABLE I-Age and sex distributions of sample

\begin{tabular}{lcccccc}
\hline & \multicolumn{4}{c}{ Age (years) } & \multirow{2}{*}{ Total } \\
\cline { 2 - 6 } & $70-74$ & $75-79$ & $80-84$ & $85+$ & \\
\hline No (\%) of men & $46(41)$ & $34(46)$ & $\left.7 \begin{array}{c}(20) \\
\text { No }(\%)\end{array}\right)$ & $5(16)$ & $92(36)$ \\
\hline Total (\%) & $112(100)$ & $74(100)$ & $35(100)$ & $32(100)$ & $253(100)$ \\
\hline
\end{tabular}

The interview questionnaire, which took on average one and a half hours to complete, was administered during one home visit to each respondent.

Deafness-Hearing loss in each ear was measured using pure-tone audiometry (air conduction) over the speech frequencies $0.25 \mathrm{kHz}$, $0.5 \mathrm{kHz}, 1 \mathrm{kHz}, 2 \mathrm{kHz}$, and $4 \mathrm{kHz}$. Masking was considered to be unnecessary. Audiocups were fitted to the Amplivox 2150 portable diagnostic audiometer used. A history was taken of any hearing impairment, the experience of deafness, and use of aids (where applicable). The audiometry was validated by the hearing-aid centre at the Royal National Throat, Nose and Ear Hospital, London, to which 44 patients were referred for hearing aids (19 requiring domiciliary visits). A high level of agreement (overall mean difference $0.3 \mathrm{db}$ ) was found between the average decibel levels of respondents retested under clinical conditions and their average levels in the field.

Mental state-Scales for screening for organic brain syndrome (dementia) and depression were extracted from the Comprehensive Assessment and Referral Evaluation (CARE) schedule ${ }^{10}$ and applied for each respondent. In their revalidation of the CARE schedule Gurland et al $^{11}$ recommend that a score of three on the dementia scale is the cut-off point that differentiates those people who would probably be clinically assessed as having some degree of dementia from those who would not. Similarly, they suggest that a score of seven or more on the depression scale is the cut-off point that differentiates those who would probably be clinically assessed as suffering from some degree of depression from those who would not. An independent psychiatrist with experience in research and psychiatry in old age carried out 10 clinical interviews to validate the application of the scales by the research team. A high level of agreement was found.

Statistical analysis-Unless otherwise stated, all significance levels were derived using a $\chi^{2}$ test.

\section{Results}

Deafness-Using as a measure of deafness the degree of impairment at which a hearing aid is normally considered to be necessary (an average loss of $35 \mathrm{db}$ or more over the speech frequencies of $1 \mathrm{kHz}$, $2 \mathrm{kHz}$, and $4 \mathrm{kHz}$ in the better ear), we established that 153 respondents $(60 \%)$ were deaf (table II). Sixty-nine per cent of those aged 75 years and over, $82 \%$ of those aged 80 years and over, and $84 \%$ of those aged 85 years and over were deaf. Thus the proportion deaf and the severity of deafness increased significantly with age $(p<$ $0.001)$. In keeping with all other studies in which no audiometry was performed, only 96 respondents $(38 \%$ ) gave a positive answer to the conventional question on hearing loss in the interview schedule.

Dementia-Of the 245 respondents in the sample who completed the questions on dementia, $39(16 \%)$ scored three or more and were thus probably suffering from some degree of dementia (table III). Of these 39 people, 19 ( $8 \%$ of the whole sample) scored five or more. 
TABLE II-Relation between advanced age and degree of deafness. Figures are numbers (\%) of respondents

\begin{tabular}{|c|c|c|c|c|}
\hline \multirow{2}{*}{ Degree of deafness } & \multicolumn{2}{|c|}{ Age (years) } & \multirow{2}{*}{\multicolumn{2}{|c|}{ Total }} \\
\hline & $70-79$ & $80+$ & & \\
\hline $\begin{array}{l}\text { 0-34 db: not deaf } \\
35-44 \mathrm{db}: \text { moderately deaf } \\
45-69 \mathrm{db}: \text { substantially deaf } \\
70+\mathrm{db}: \text { severely deaf }\end{array}$ & $\begin{array}{ll}88 & (47) \\
38 & (20) \\
47 & (25) \\
13 & (7)\end{array}$ & $\begin{aligned} 12 & (18) \\
8 & (12) \\
34 & (51) \\
13 & (19)\end{aligned}$ & $\begin{array}{r}100 \\
46 \\
81 \\
26\end{array}$ & $\begin{array}{l}(40) \\
(18) \\
(32) \\
(10)\end{array}$ \\
\hline Total & $186(100)$ & $67(100)$ & 253 & (100) \\
\hline
\end{tabular}

$\chi^{2}=30.09 ; \mathrm{df}=3 ; \mathrm{p}<0.001$

TABLE III-Relation between age and dementia. Figures are numbers (\%) of respondents

\begin{tabular}{|c|c|c|c|c|c|c|}
\hline \multirow{2}{*}{\multicolumn{2}{|c|}{ Degree of dementia }} & \multicolumn{3}{|c|}{ Age (years) } & \multirow{2}{*}{\multicolumn{2}{|c|}{ Total }} \\
\hline & & \multicolumn{2}{|c|}{$70-79$} & $80+$ & & \\
\hline $\begin{array}{l}\text { Not demented } \\
\text { Mild dementia } \\
\text { Pronounced dementia }\end{array}$ & $\begin{array}{l}\ldots \\
\cdots\end{array}$ & $\begin{array}{r}163 \\
15 \\
2\end{array}$ & $\begin{array}{r}(91) \\
(8) \\
(1)\end{array}$ & $\begin{array}{rr}43 & (66) \\
5 & (8) \\
17 & (26)\end{array}$ & $\begin{array}{r}206 \\
20 \\
19\end{array}$ & $\begin{array}{r}(84) \\
(8) \\
(8)\end{array}$ \\
\hline Total & & 180 & $100)$ & $65(100)$ & 245 & (100) \\
\hline
\end{tabular}

$\chi^{2}=42.02 ; \mathrm{df}=2 ; \mathrm{p}<0.001$.

All but one of these 19 were adjudged at interview to be giving unreliable responses because of mental frailty. This was regarded by the research team as justification for taking a score of five as an additional cut-off point denoting a division between mild and pronounced dementia. These figures for the prevalence of dementia are comparable with those of other studies reviewed by Gilmore. ${ }^{12}$ As expected, a significant relation was found between increased age and the prevalence and severity of dementia $(p<0.001)$.

Deafness and dementia-Thirty-one $(79 \%)$ of the 39 respondents with dementia were also deaf (table IV). A significant relation was found between deafness and dementia $(p<0.01)$. As people get more deaf they are significantly more likely to be demented $(\mathrm{p}<0.05)$. These results, however, do not support the suggestion of Kay et al that the connection between deafness and dementia is "too strong to be wholly explicable by advanced age." Once age is controlled for the apparent relation is lost (table V). Deafness and dementia appear to be merely contiguous conditions; both are functions of age.

Depression-Of the 235 respondents who completed the full depression scale, $82(35 \%)$ scored seven or more and thus may be taken as suffering from at least "limited" depression. Of these 82 respondents, 25 (11\% of the sample) scored 14 or more and may be taken as suffering from "pervasive" depression. These figures for the

TABLE IV-Relation between severity of hearing loss and dementia. Figures are numbers (\%) of respondents

\begin{tabular}{|c|c|c|c|c|c|c|c|c|}
\hline \multirow[b]{3}{*}{$\begin{array}{l}\text { Not demented } \\
\text { Mild and pronounced dementia }\end{array}$} & \multicolumn{6}{|c|}{ Degree of deafness } & \multirow{2}{*}{\multicolumn{2}{|c|}{ Total }} \\
\hline & \multicolumn{2}{|c|}{$\begin{array}{c}\text { Not } \\
\text { deaf } \\
(0-34 \mathrm{db})\end{array}$} & \multicolumn{2}{|c|}{$\begin{array}{l}\text { Moderately and } \\
\text { substantially deaf } \\
(35-69 \mathrm{db})\end{array}$} & \multicolumn{2}{|c|}{$\begin{array}{c}\text { Severely } \\
\text { deaf } \\
(70+\mathrm{db})\end{array}$} & & \\
\hline & $\begin{array}{r}87 \\
8\end{array}$ & $\begin{array}{r}(92) \\
(8)\end{array}$ & $\begin{array}{r}101 \\
24\end{array}$ & $\begin{array}{l}(81) \\
(19)\end{array}$ & $\begin{array}{r}18 \\
7\end{array}$ & $\begin{array}{l}(72) \\
(28)\end{array}$ & $\begin{array}{r}206 \\
39\end{array}$ & $\begin{array}{l}(84) \\
(16)\end{array}$ \\
\hline Total & 95 & $(100)$ & 125 & (100) & 25( & (100) & 245 & $(100)$ \\
\hline
\end{tabular}

$\chi^{2}=7 \cdot 72 ; \mathrm{df}=2 ; \mathrm{p}<0.05$. prevalence of depression are higher than those found in other community studies, ${ }^{1: 314}$ but this may be partly explained by the greater age of the respondents in the present study and the consequently higher proportion of women, among whom depression is apparently more common. ${ }^{13}$ When the two categories of depression were combined a significant relation was found between age and depression (table VI), but there was no association between age and the severity of depression. The 19 respondents assessed as suffering from pronounced dementia were excluded from all further analysis of depression since their responses at interview were judged to be unreliable.

TABLE VI-Relation between age and depression. Figures are numbers (\%) of respondents

\begin{tabular}{lrrrrr}
\hline & \multicolumn{3}{c}{ Age (years) } & \multirow{2}{*}{ Total } \\
\cline { 2 - 4 } & \multicolumn{2}{c}{$70-79$} & $80+$ & \\
\hline Not depressed & $120(69)$ & $33(54)$ & $153(65)$ \\
Limited and pervasive depression & $54(31)$ & 28 & $(46)$ & $82(35)$ \\
\hline Total & $174(100)$ & $61(100)$ & $235(100)$ \\
\hline
\end{tabular}

$\chi^{2}=4.39 ; \mathrm{df}=1 ; \mathrm{p}<0.05$

Deafness and depression-Fifty $(69 \%)$ of the 72 respondents who were depressed were also deaf. A significant relation was found (table VII) between deafness and depression $(\mathrm{p}<0.01)$. No relation could be found, however, between the severity of depression and the severity of deafness. When age and socioeconomic state were controlled for (using ANOVA, a subprogram of the Statistical Package for the Social Sciences for analysis of variance) a significant relation between deafness and depression remained (using an adjusted $\gamma^{2}$ test $\left.\mathrm{p}<0 \cdot 05\right)$.

TABLE VII-Relation between depression and deafness. Figures are numbers (\%) of respondents

\begin{tabular}{lccc}
\hline & \multicolumn{2}{c}{ Depression } & Total \\
\cline { 2 - 3 } & $\begin{array}{c}\text { Not } \\
\text { depressed }\end{array}$ & $\begin{array}{c}\text { Limited and } \\
\text { pervasive depression }\end{array}$ & \\
\hline $\begin{array}{l}\text { Not deaf }(0-34 \mathrm{db}) \\
\text { Deaf }(35+\mathrm{db})\end{array}$ & $73(50)$ & $50(69)$ & $123(57)$ \\
\hline Total & $145(100)$ & $72(31)$ & $94(43)$ \\
\hline
\end{tabular}

$\chi^{2}=6.39 ; \mathrm{df}=1 ; \mathrm{p}<0.01$.

\section{Discussion}

The use of audiometric techniques to assess the prevalence of deafness yielded estimates almost double those produced by other studies, all of which relied solely on' self-reporting by patients or clinical judgment. This gross discrepancy was confirmed by the only two comparable studies in which audiometry was used, both of which were concerned with the elderly in residential institutions ( $\mathrm{D} \mathrm{K}$ Burton, unpublished results). ${ }^{15}$ Considerable doubt is cast, therefore, on the validity of all studies estimating the prevalence of deafness when audiometry is not carried out.

TABLE V-Dementia by degree of deafness, controlling for age. Figures are numbers (\%) of respondents

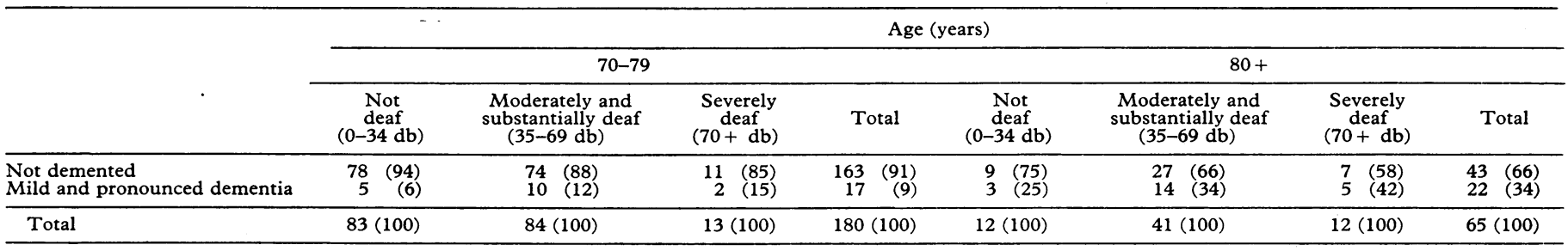

Significance of difference between respondents with and without dementia-Those aged 70-79: $\chi^{2}=2 \cdot 27 ; \mathrm{df}=2 ; \mathrm{NS}$. Those aged 80 and over: $\chi^{2}=0 \cdot 75 ; \mathrm{df}=2 ; \mathrm{NS}$. 
Contrary to the suggestions of other researchers and to conventional belief, we could find no relation between deafness and dementia. An explanation for this is probably that audiometry was not performed in any previous studies looking at the possible aetiology of dementia. Although the present study showed an apparently closer relation between deafness and dementia than other studies, in that $79^{\circ} \%$ of the respondents with dementia were also deaf, it also showed for the first time that deafness is the norm and not the exception, particularly in those aged over 80 . Some link may possibly exist between dementia and deafness of early onset. As a strong component of dementia is poor memory recall, however, without recourse to longitudinal studies using audiometric techniques causal associations cannot be made.

Two main implications arise for diagnosing and managing mental disorders in the elderly in the community. The first concerns the increasingly common practice for both research and clinical purposes of using screening devices, in the form of standardised tests, as an aid to establishing the presence of mental disorders, particularly dementia..$^{16-18}$ Indeed, we used such a device in the present study. Many compilers of these measures caution would-be users that the tests, being essentially verbal, may be unsuitable for deaf subjects. ${ }^{1719}$ Since $82 \%$ of those aged 80 and over and $89 \%$ of those with pronounced dementia in this study were deaf (table VIII), the validity of all such screening devices would seem to be questionable.

TABLE VIII-Relation between severity of dementia and deafness. Figures are numbers $(\%)$ of respondents

\begin{tabular}{|c|c|c|c|c|}
\hline \multirow[b]{3}{*}{$\begin{array}{l}\text { Not deaf }(0-34 \mathrm{db}) \\
\text { Deaf }(35+\mathrm{db})\end{array}$} & \multicolumn{3}{|c|}{ Dementia } & \multirow{2}{*}{ Total } \\
\hline & $\begin{array}{c}\text { Not } \\
\text { demented }\end{array}$ & $\begin{array}{c}\text { Mild } \\
\text { dementia }\end{array}$ & $\begin{array}{l}\text { Pronounced } \\
\text { dementia }\end{array}$ & \\
\hline & $\begin{array}{r}87(42) \\
119 \quad(58)\end{array}$ & $\begin{aligned} 6 & (30) \\
14 & (70)\end{aligned}$ & $\begin{aligned} 2 & (11) \\
17 & (89)\end{aligned}$ & $\begin{aligned} 95 & (39) \\
150 & (61)\end{aligned}$ \\
\hline Total & $206(100)$ & $20(100)$ & $19(100)$ & $245(100)$ \\
\hline
\end{tabular}

$\%^{2}=8.07 ; \mathrm{df}=2 ; \mathrm{p}<0.05$

Nevertheless, tackling assessment and diagnostic procedures firmly expecting deafness in nearly all patients with dementia and most elderly patients with depression should overcome this problem.

We found that severely deaf respondents were initially loth to make the effort to respond to the interview questionnaire until they realised that their communication difficulties were fully appreciated and would be allowed for. This raises questions about the positioning in interviews of tests for dementia, which require maximum concentration and yet are frequently placed too early for good rapport to have been established between patient and clinician. It is essential to use great care, patience, and ingenuity to ensure maximum audibility and visibility of the spoken word and to be prepared, if necessary, to use the written word. Conventional clinical techniques may prove inadequate, in which case probably no assumptions about mental state should be made without carrying out audiography. There is a danger of regarding, and therefore treating, elderly people as demented or confused when they are actually severely deaf, particularly as the manifestations of both these disorders are in many ways so similar. Such fears have already been voiced by researchers, particularly with regard to residents in local authority homes for the elderly. ${ }^{20} 21$

The second matter concerns management and treatment of people with impaired hearing. Not wearing a hearing aid does not appear to worsen the impairment-that is, the degree of deafness. Without an aid, however, the social and psychological effects of deafness-namely, withdrawal, depression, and the frustration of other people-are unalleviated and may feed back into the disorder, accentuating alienation and discrimination.

This study is unremarkable in its finding that only $13 \%$ of the elderly population (of whom $60 \%$ were deaf) possessed hearing aids; thus there is evidently vast scope for action. While deafness is not a major cause of depression in old age, it is certainly a contributing factor and one that may be more readily ameliorated than many others.

We thank the Nuffield Foundation for funding the study and the Polytechnic of North London for its support. Thanks are due to the doctors of the general practice concerned for granting access to their patients; and to the receptionist at the practice, without whose generous help the study could not have been carried out. Much gratitude is also due to Ms J Stevenson and Ms S Faruqi, research assistants to the study, and to Dr E Murphy, who validated our administration of the CARE schedule.

\section{References}

1 Townsend P, Wedderburn D. The aged in the welfare state. Occasional papers on social administration. No 14. London: G Bell, 1965.

${ }^{2}$ Abrams M. Beyond three-score and ten. A first report on a survey of the elderly. Mitcham: Age Concern, 1978.

${ }^{3}$ Sheard AV. Survey of the elderly in Scunthorpe. Public Health 1971; 85:208-18.

${ }^{4}$ Williamson J, Stokoe IH, Gray S, et al. Old people at home: their unreported needs. Lancet 1964 ; i:1117-20.

${ }^{5}$ Advisory Committee on Services for Hearing-impaired People. Report of a sub-committee appointed to consider the work of social services in the care of the deaf of all ages. London: Department of Health and Social Security, 1977.

${ }^{6}$ Kay DWK, Beamish P, Roth M. Old age mental disorders in Newcastle upon Tyne. II. A study of possible social and medical causes. $\mathrm{Br} \mathcal{J}$ Psychiatry 1964;110:668-82.

${ }^{7}$ Hodkinson HM. Mental impairment in the elderly. $\mathcal{F} R$ Coll Physicians Lond 1973;7:305-17

${ }^{8}$ Garland MH. Depression and dementia. Hospital Update 1978 June: 313-9.

${ }^{9}$ Charatan FB. Depression in old age. NY State 7 Med 1975;75:2505-7.

${ }^{10}$ Gurland BJ, Kuriansky JB, Sharpe L, Simon R, Stiller P, Birkett P. The comprehensive assessment and referral evaluation (CARE) rationale, development and reliability. Int f Aging Hum Dev 1977 8:9-42.

11 Gurland BJ, Sharpe L, Simon R, et al. A cross-national comparison between New York and London of the frequency, management and outcome of psychiatric, medical and social problems among the elderly living in the community. New York: Haworth Press (in press).

12 Gilmore AJJ. Community surveys and mental health. In: Anderson WF, Judge TG, eds. Geriatric medicine. London: Academic Press, 1974 .

${ }^{13}$ Kay DWK, Beamish P, Roth M. Old age mental disorders in Newcastle upon Tyne. I. A study of prevalence. Brf Psychiatry 1964;110:146-58.

${ }^{14}$ Blessed G. Depression: assessing the patient behind the mask. Geriatric Medicine 1979 May:29-32.

15 Martin DN, Peckford RW. Hearing impairment in homes for the elderly. Social Work Service 1978;17:52-62.

${ }^{16}$ Blessed G, Tomlinson BE, Roth $M$. The association between quantitative measures of dementia and of senile change in the cerebral grey matter of elderly subjects. Br $\mathcal{F}$ Psychiatry $1968 ; 114: 797-811$.

17 Isaacs B, Kennie A. The set test as an aid to the detection of dementia in old people. Br F Psychiatry 1973;123:467-70.

${ }^{18}$ Hopkins B, Roth M. Psychological test performance in patients over sixty. Part II. Paraphrenia, arteriosclerotic psychosis and acute confusion. Fournal of Mental Science 1953;99:451-63.

19 Irving G, Robinson RA, McAdam W. The validity of some cognitive tests in the diagnosis of dementia. Br F Psychiatry 1970;117:149-56.

20 Townsend P. The last refuge. London: Routledge and Kegan Paul, 1964.

${ }^{21}$ Martin DN, Peckford RW. Hearing impairment in homes for the elderly. Northallerton: North Yorkshire County Council Social Services Department, 1977.

(Accepted 20 August 1980)

ONE HUNDRED YEARS AGO We are requested to announce that the full-sized clay model of the statue of Harvey, which is to be erected at Folkestone, has nearly approached completion; and that the sculptor, Mr A B Joy, invites the subscribers to the Harvey Tercentenary Memorial Fund to a private view of the model (upon presentation of address cards) on Wednesday next, August 4th, from 11 to 5.30 o'clock, at his studio, No. 8, The Avenue, 76 Fulham Road, SW. (British Medical Fournal, 1880.) 